\title{
Artigos
}

\section{Passagem de plantão em um serviço hospitalar de emergência: perspectivas de uma equipe multiprofissional}

\author{
Shift turn in a hospital emergency service: perspectives of a \\ multiprofessional team (abstract: p. 16)
}

Entrega del turno en el servicio de urgencia y emergencia: perspectivas de un equipo multiprofesional (resumen: p. 16)

\author{
Vanessa Schorr ${ }^{(a)}$ \\ <vanessa.schorr@yahoo.com.br> (iD \\ Luciara Fabiane Sebold(b) \\ $<$ fabisebold@gmail.com> iD \\ José Luís Guedes dos Santos(c) \\ <jose.santos@ufsc.br>
}

Keyla Cristiane do Nascimento(d)

<keyla.n@ufsc.br>

Thaís Alves Matos ${ }^{(\mathrm{e})}$

$<$ thais.alves.matos@gmail.com>

\author{
(a) Pós-graduanda do Programa \\ de Pós-Graduação em \\ Enfermagem (mestrado), \\ Departamento de \\ Enfermagem, Centro de \\ Ciências da Saúde (CCS), \\ Universidade Federal de \\ Santa Catarina (UFSC). Rua \\ Delfino Conti, $s / n^{\circ}$, Trindade. \\ Florianópolis, SC, Brasil. \\ 88040-900. \\ $(b, c, d)$ Departamento de \\ Enfermagem, CCS, UFSC \\ Florianópolis, SC, Brasil. \\ (e) Enfermeira. Florianópolis, \\ $\mathrm{SC}$, Brasil.
}

Objetivou-se conhecer a perspectiva da equipe multiprofissional sobre a passagem de plantão no serviço de emergência de um hospital universitário. Estudo exploratório e descritivo, com abordagem qualitativa. Foram entrevistados 15 integrantes da equipe multiprofissional. Por meio da técnica de análise de conteúdo, identificaram-se duas categorias: importância da participação ativa da equipe multiprofissional para o momento da passagem de plantão; e ausência de padronização das informações na passagem de plantão para a segurança do paciente na continuidade do cuidado. Os resultados apontam pouca contribuição da equipe multiprofissional na passagem de plantão, podendo estar relacionada com a cultura organizacional. A confiança interprofissional, a promoção de espaço que favoreça a contribuição da equipe multiprofissional com falas e momentos para tirar dúvidas e a assiduidade da equipe são aspectos abordados como facilitadores para uma passagem de plantão efetivamente multiprofissional.

Palavras-chave: Comunicação. Segurança do paciente. Continuidade da assistência ao paciente. Equipe de assistência ao paciente. Enfermagem em emergência.

Schorr V, Sebold LF, Santos JLG, Nascimento KC, Matos TA. Passagem de plantão em um serviço hospitalar de emergência: perspectivas de uma equipe multiprofissional. Interface (Botucatu). 2020; 24: e190119 https://doi.org/10.1590/Interface.190119 


\section{Introdução}

A atuação na área da saúde é permeada de subjetividade, essencialmente relacional, que agrega tecnologias leves, leves-duras e duras no processo saúde-doença-cuidado ${ }^{1}$. As inovaçóes e o desenvolvimento da tecnologia e da ciência influenciam a vida em sociedade, gerando transformaçóes na área da saúde, no meio ambiente, no comportamento das pessoas e na vida social. O campo da saúde é altamente proficiente em relação ao desenvolvimento científico e tecnológico, associado à produção e utilização de bens e serviços ${ }^{2}$. Em consequência, exige-se dos trabalhadores uma formação de qualidade, educação permanente e competências específicas para o atendimento de demandas do mercado de trabalho ${ }^{1}$.

No contexto do mercado de trabalho na saúde é imprescindível que a comunicação seja a base das relaçôes. Neste cenário de atenção à saúde, destaca-se a passagem de plantão como parte importante do processo de trabalho na saúde no ambiente hospitalar. É um momento em que a equipe multidisciplinar compartilha informações da assistência prestada aos usuários e revê condutas, atualizando os integrantes da equipe sobre o estado de saúde do usuário e funcionamento da unidade 3 .

A passagem de plantão representa uma importante ferramenta de acesso à informação e permite melhorar o processo de trabalho, podendo também subsidiar as diferentes categorias profissionais envolvidas no cuidado, como psicologia, nutrição, farmácia, serviço social, entre outras ${ }^{4}$. Para que a passagem de plantão seja realizada de forma eficaz, deve-se ter um trabalho de equipe bem articulado e com roteiro de informaçóes estruturado. Assim, torna-se possível a criação de alternativas eficientes para a transmissão de informaçốes de maneira mais consciente 5 .

A passagem de plantão é uma forma de comunicação que ocorre na troca de turnos e promove a transferência de responsabilidades assistenciais de usuários de uma equipe multiprofissional para outra ${ }^{3}$. Esse movimento de troca de informaçôes envolve o processo de gerenciamento e a comunicação representa uma importante ferramenta no trabalho em saúde de toda a equipe multidisciplinar. Uma comunicação eficaz garante segurança para a continuidade das atividades pela equipe multiprofissional que exerce suas funções em diversos turnos de trabalho, oferecendo melhor qualificação do serviço e o cumprimento da responsabilidade na prestação de assistência à saúde de forma interprofissional e multidisciplinar ${ }^{4}$.

Sendo assim, torna-se necessário que as instituiçôes de saúde criem uma concisa cultura de segurança do paciente no ambiente de serviço por meio da reorientação do processo de trabalho e da contínua atualização dos profissionais de saúde ${ }^{6}$.

Porém, a produção científica nacional e internacional sobre esse tema ainda é escassa. Identificou-se um estudo de revisão integrativa sobre aspectos facilitadores e dificultadores acerca da passagem de plantão de enfermagem no âmbito hospitalar ${ }^{3}$. Além disso, evidenciaram-se na literatura estudos anteriores sobre passagem de plantão, contudo, considerando-se outros cenários, como exemplo de unidade de terapia intensiva ${ }^{5}$ e unidades de cuidados intensivos neonatais ${ }^{6}$. Nenhum estudo foi encontrado entre os anos de 2013 a 2018 que tratasse da 
passagem de plantão em serviço hospitalar de emergência, considerando-se a visão da equipe multiprofissional. Nesse sentido, o presente estudo representa grande relevância e inovação, considerando essa temática e a integralidade do cuidado na assistência multiprofissional ao paciente em cenário hospitalar de emergência.

Tendo em vista o exposto anteriormente e considerando que uma passagem de plantão de qualidade interfere diretamente na qualidade da assistência prestada aos usuários, este estudo justifica-se pela busca constante de melhorias nos processos de comunicação entre as equipes multiprofissionais no cenário de atuação de urgência e emergência, com vista à segurança do usuário. Isso torna fundamental uma atuação articulada entre as principais esferas envolvidas para o desenvolvimento de ações positivas para a segurança do paciente, com a criação de estratégias que minimizem os riscos, garantindo um cuidado seguro e de qualidade ${ }^{6}$.

Nesse sentido, o presente estudo teve por objetivo conhecer a perspectiva da equipe multiprofissional da saúde sobre a passagem de plantão do serviço hospitalar de emergência de um hospital universitário do Sul do Brasil.

\section{Metodologia}

Trata-se de um estudo exploratório e descritivo, com abordagem qualitativa. O local da pesquisa foi um serviço hospitalar de emergência de um Hospital Universitário do Sul do Brasil, que atende pacientes adultos exclusivamente pelo Sistema Único de Saúde. A equipe de saúde desse serviço é composta de 55 profissionais, sendo 42 na condição de contratados e 13 residentes do Programa de Residência Integrada Multiprofissional em Saúde.

Os participantes do estudo foram 15 profissionais de saúde que atuavam no serviço supracitado. Adotou-se como critério de inclusão tempo mínimo de seis meses de trabalho no setor. Considerou-se como critério de exclusão ausência decorrente de férias ou licença de qualquer natureza. A equipe de medicina não foi incluída no estudo devido à passagem de plantão desses profissionais ocorrer em horários diferentes da passagem de plantão realizada pela enfermagem.

A coleta dos dados deu-se por meio de entrevistas semiestruturadas com os profissionais integrantes da equipe multiprofissional. Participaram do estudo cinco enfermeiros, um técnico de enfermagem, dois psicólogos, dois nutricionistas, dois assistentes sociais e três farmacêuticos. A quantidade de entrevistados foi avaliada como suficiente para a realização das análises a partir do critério de saturação, uma vez que foi observada a repetição do conteúdo nos relatos dos participantes, verificando-se, nas falas, que as percepçóes relacionadas à passagem de plantão não traziam novos conteúdos para análise.

Para manter o rigor do estudo foram utilizados os critérios estabelecidos para o Reporting Pesquisa Qualitativa (COREQ) ${ }^{7}$. As entrevistas foram conduzidas por uma residente de enfermagem do segundo ano do Programa de Residência Integrada Multiprofissional em Saúde, entre julho e novembro de 2018, conforme roteiro com questionamentos relacionados à metodologia empregada pelos profissionais do serviço para a realização da passagem de plantão, as informações que são repassadas 
e como se dá a participação dos integrantes da equipe multiprofissional na passagem de plantão. Os profissionais foram pessoalmente convidados a participar do estudo e o espaço físico utilizado para a realização das entrevistas foram consultórios, promovendo um espaço sem ruídos e sem a presença de outros indivíduos.

O tempo das entrevistas variou de $10 \mathrm{~min} 32 \mathrm{~s}$ a $32 \mathrm{~min} 27 \mathrm{~s}$, com uma mediana de tempo de $16 \mathrm{~min} 08 \mathrm{~s}$. Vale ressaltar que foram realizadas cinco entrevistas-piloto com profissionais da instituição com vistas ao aprimoramento dos instrumentos e posterior início da pesquisa, sendo que estas não foram contempladas para análise.

As entrevistas foram gravadas em dispositivo eletrônico de áudio e posteriormente transcritas no programa de digitação Microsoft Word®.

Com o material transcrito e revisado, foi aplicada a técnica de análise de conteúdo, com o referencial teórico baseado em $\mathrm{Minayo}^{8}$. A análise e tratamento do material empírico e documental dizem respeito ao conjunto de procedimentos para compreender, interpretar e articular os dados empíricos com a teoria, sendo realizados em três tipos de procedimentos: ordenação dos dados, classificação dos dados e análise propriamente dita. Para a etapa de elaboração de categorias, realizou-se a análise de conteúdo em três etapas: pré-análise, exploração do material e tratamento dos resultados obtidos/inferência/interpretação ${ }^{8}$.

Por meio da categorização, foram iniciadas as interpretações, possibilitando respostas à pergunta de pesquisa, objetivando compreender os significados e percepçôes do contexto estudado. Para a apresentação dos trechos das entrevistas nos resultados do estudo, e como forma de manter o anonimato, os entrevistados foram designados com a inicial "E”, procedida da sigla da categoria profissional do entrevistado.

A pesquisa seguiu a Resolução no 466/2012 do Conselho Nacional de Saúde sobre pesquisas envolvendo seres humanos ${ }^{9}$. Desse modo, o projeto de pesquisa foi submetido à avaliação do Comitê de Ética em Pesquisa via Plataforma Brasil, sendo aprovado sob o número do parecer no 2.562.778.

\section{Resultados}

No tratamento dos resultados, identificaram-se as seguintes categorias: Participação ativa da equipe multiprofissional para a passagem de plantão; e Ausência de padronização das informações na passagem de plantão para a segurança do paciente.

\section{Participação ativa da equipe multiprofissional para a passagem de plantão}

Esta categoria descreve como os participantes da pesquisa consideram relevante a participação de todos os integrantes da equipe multiprofissional durante a passagem de plantão, considerando-os não apenas como ouvintes, mas também como participantes ativos, no sentido de contribuir com falas e informaçóes relacionadas aos pacientes, aproveitando mais este momento. A passagem de plantão também é considerada um momento para tirar dúvidas, como se observa nos depoimentos a seguir: 
Eu acho que pode ser um momento para discussão de alguma dúvida ou de algum caso. Eu acho que muitas vezes fica muito fechado e as pessoas ficam com receio de falar, de perguntar alguma coisa e de ficar em tom de crítica. Poderia ser algo mais aberto, não que fuja do tema. (E4ENF)

Eu acho que em alguns momentos surgem dúvidas, que podem ser dúvidas pequenas, que dá para a gente resolver rápido, se for alguma coisa que precisa prolongar assim, daí a gente pode ter em outro momento. (E5FARM)

[...] eu acho que nos casos necessários eles poderiam dar a devolutiva, por exemplo, às vezes a gente tem paciente com risco suicida, então a psicologia poderia passar um pouquinho sobre esse paciente. (E4ENF)

[...] aqui acaba não tendo uma troca, acaba sendo só passar aquilo e não tem abertura para contribuiçóes do restante dos profissionais. Acho que nesse sentido a gente poderia trocar mais, muitas vezes eu acabo ficando quieta e eu acho que esse espaço poderia ser mais bem aproveitado. (E7PSICO)

Os participantes do estudo destacam ainda a importância da passagem de plantão para que se possa traçar o plano de cuidados aos pacientes, sendo esta a primeira comunicação da equipe e um dos momentos mais importantes do dia no serviço:

[...] se não for o momento mais importante do dia, talvez seja um dos momentos mais importantes do dia, é uma primeira comunicação para você iniciar o serviço. [...] Através da passagem de plantão é que a gente traça toda a estratégia do dia, com relação àqueles pacientes. [...] É captado ali de maneira geral tudo o que você pode fazer pelo paciente como multi, embora seja, assim, muito restrito à enfermagem essa passagem de plantão, deveria ser feito algumas observaçóes pela própria equipe multi, o que não ocorre. (E9FARM)

Eu acho que de certa forma todo mundo acaba, a partir dali que consegue organizar e fazer o seu planejamento do trabalho do dia. (E12SSO)

Os participantes do estudo destacam a predominância de contato com o paciente por parte da enfermagem - o que proporciona maior captação de demandas por esta categoria profissional - e reconhecem a necessidade da participação da equipe multiprofissional durante a passagem de plantão para oferecer um suporte e sustentação, sendo esta uma oportunidade de intervençóes dos integrantes da equipe para que não ocorram falhas durante o cuidado aos pacientes. Nesse sentido, a falta de adesão dos integrantes da equipe multiprofissional na passagem de plantão representa uma diminuição da qualidade da assistência prestada aos pacientes e familiares e compromete o vínculo com o restante da equipe: 
A enfermagem é quem mais está em contato com o paciente ali, se não o tempo todo, 99\% do tempo, não é medicina, não é farmácia, não é serviço social e nem psicologia, é a enfermagem. Então, é interessante que a gente dê esses toques também para a enfermagem, para que vocês [enfermeiros] consigam ali associar uma coisa à outra, porque a correria é grande e a gente sabe, a gente entende. Então a gente tem que estar realmente como um suporte ali, não pode deixar vocês (enfermeiros) caminhando sozinhos, porque se não em algum momento vai falhar. A equipe multiprofissional ela é para se sustentar, então não só para a passagem de plantão, mas o momento todo [...]. Então é um momento crucial assim, eu acho de extrema importância realmente. (E9FARM)

[...] a equipe de enfermagem está ali o tempo todo, está o plantão inteiro ali só naquele espaço, consegue observar melhor as demandas dos pacientes e das famílias. Às vezes a gente nem sempre está ali o tempo todo, a gente tem a sala do serviço social. Às vezes a gente está de plantão em todo o hospital, então acaba sendo diferente o contato que vocês [enfermeiros] têm com o paciente e o contato que a gente tem também. Então vocês [enfermeiros] conseguem identificar e passar isso para a gente, então eu acho que a falta de adesão dos profissionais ali é uma perda para a equipe, para os pacientes e para os familiares e acompanhantes que estão ali, então é importante que a gente participe até para ter uma vinculação maior com a equipe, não só a gente do serviço social, mas como a equipe multi. (E13SSO)

Outro aspecto levantado pelos participantes do estudo é a possibilidade de espaços de participação na passagem de plantão pela enfermagem, que se configura como contribuiçóes dos integrantes da equipe multiprofissional, e essa abertura depende do profissional que está proferindo a passagem de plantão. Pode-se relacionar este achado com a confiança interprofissional que os indivíduos estabelecem em suas relaçôes de trabalho, como observado nas falas a seguir:

Às vezes esses outros profissionais têm espaço para contribuírem com informações durante a passagem de plantão, mas vai de acordo com a pessoa que está passando o plantão também, porque tem gente que passa com mais pressa, então se surge alguma conversa ela é cortada rápido. (E5FARM)

O enfermeiro vai falar, por exemplo, "Tem uma demanda para vocês do serviço social”, mas ele não abre um espaço para o serviço social comentar o que ele disse e o enfermeiro fica com uma cara do tipo "Anda logo que eu quero acabar aqui", então eu não sinto que abre espaço, eu não me sinto à vontade para falar, tanto que eu nem falo. (E14NUTRI)

Então talvez aproveitar esse momento da passagem de plantão para de fato discutir a situação do paciente, de ter esse cuidado de perceber que o paciente 
não é só uma partezinha, por isso que a gente tem uma equipe multi e cada profissional vai identificar suas demandas e a partir disso vai trabalhar e verificar o que pode ser fornecido nessa rede de serviços. (E13SSO)

Os participantes do estudo relatam como ocorre atualmente a passagem de plantão no cenário de estudo, sendo que as informaçóes são repassadas com base nos registros das folhas de observaçôes complementares utilizados pela equipe de enfermagem, como observado nos seguintes depoimentos:

Nós passamos o plantão com uma folha que a gente tem, de evolução... folha de observações, dividido em manhã, tarde e noite, de observações onde a gente registra tudo que a gente observa do paciente e tudo que acontece com o paciente, e a gente usa essa folha de observação para passar o plantão, mas um formulário específico não tem. (E3ENF)

Nesta categoria, podemos observar o quão importante é, para o cuidado e a segurança do paciente, a troca de informaçóes de todos profissionais da equipe multiprofissional.

\section{Ausência de padronização das informações na passagem de plantão para a segurança do paciente}

Os participantes do estudo apontaram para a ausência de uma padronização no processo da comunicação da passagem de plantão para turnos de trabalhos subsequentes, considerando uma perspectiva multiprofissional. Apesar disso, os profissionais percebem a importância de haver uma padronização da passagem de plantão, considerando este instrumento como facilitador para o processo de comunicação, como pode ser visualizado nos seguintes depoimentos:

Não existe uma metodologia específica para passagem de plantão, o enfermeiro é que faz a passagem de plantão e não tem nada multiprofissional assim. [...] Não tem nada específico para outras profissóes, ou seja, multiprofissional, e sim de enfermeiro para enfermeiro, mas as outras profissóes também participam da passagem de plantão. (E2ENF)

Com certeza eu acho que deveria ter alguma instrução e que os profissionais que passassem o plantão estivessem cientes desse Procedimento Operacional Padrão. Tem Procedimento Operacional Padrão de passagem de plantão da emergência? (E6FARM) 
Não conheço nenhum Procedimento Operacional Padrão de passagem de plantão. Eu acho que poderia ser criado algo para melhorar a passagem de plantão, mas eu não sei como ficaria a gestão do tempo, porque tem gente saindo e tem gente entrando, e as pessoas estão meio que querendo que aquilo termine rápido para ir trabalhar ou para ir embora. (E10PSICO)

Em alguns depoimentos observou-se que os profissionais até já ouviram falar da existência de um Procedimento Operacional Padrão sobre passagem de plantão no hospital. Porém, não têm conhecimentos aprofundados acerca deste, revelando que as atividades de educação permanente no serviço precisam ser mais enfatizadas.

[...] a gente acaba se baseando na folha das observaçôes complementares, naqueles registros que estão ali, cada um acaba fazendo de uma forma, relatando ali, escrevendo de uma forma, acaba não tendo uma coisa padronizada e formal assim. (E4ENF)

Eu não conheço do hospital se existe algum protocolo para passagem de plantão, até na reunião do Grupo de Apoio Pedagógico teve essa questão e daí eu fiquei sabendo que tinha algum documento, porque até então eu não sabia. (E7PSICO)

A gente tem um Procedimento Operacional Padrão na emergência sobre passagem de plantão, se eu não me engano ele descreve os passos só que daí poucas as vezes, para quem entra, não sei se ele é diretamente apresentado, tanto que eu fui descobrir esse Procedimento Operacional Padrão um tempo depois, e daí acaba sendo um Ctrl C + Ctrl V. Muitas das vezes, quando a pessoa entra, um novo, tanto residente ou quando funcionário novo entra, ele observa a maneira de como é passado no primeiro momento, e depois ele começa a meio que lembrar da forma que é e acaba passando da mesma forma. Não sei se no Procedimento Operacional Padrão trata alguma coisa sobre a passagem de plantão multiprofissional, essa informação vou ficar te devendo, porque eu vi mas não detalhei se fala de equipe multidisciplinar, não sei se é propriamente destinado para a enfermagem. (E11ENF)

Eu não tenho um conhecimento enorme sobre o protocolo de passagem de plantão, mas eu sei que existe um protocolo, e se pelo menos fosse falado exatamente tudo na mesma ordem, tudo de uma forma organizada e não deixar de falar sobre nada, porque, por exemplo, tem uma enfermeira que fala sempre da alimentação, que o paciente aceitou bem o lanche da noite ou que recusou o lanche da noite, e tem outros que nunca falam nada sobre alimentação. (E14NUTRI) 
Os depoimentos dos participantes também indicam como eles realizam a transferência das informaçôes aos demais integrantes da equipe multiprofissional, sendo que esta ocorre predominantemente de forma verbal:

A maioria das vezes é verbal, a não ser quando a gente passa para o enfermeiro que anota na fichinha, mas tirando isso, de técnico para técnico na maioria das vezes é verbal. E esse registro das informações complementares fica disponível para toda equipe. (E8TECENF)

Quando precisa passar alguma coisa para a equipe, a gente vai falando para todo mundo mesmo, é porque a gente ali, na farmácia, a gente não tem nada que vá para o prontuário, então tudo o que a gente acaba resolvendo a gente meio que conversa com o médico e na hora a gente comenta e resolve. (E5FARM)

De forma verbal de pessoa a pessoa. Tem uma forma de registro para a equipe farmacêutica sim, mas para a equipe multiprofissional não, ainda não temos a evolução farmacêutica no prontuário, esse é um próximo passo da farmácia clínica. (E9FARM)

Os participantes do estudo consideram que a comunicação é um processo complexo e apontam para a necessidade de uma metodologia de passagem de plantão que pudessem padronizar as informaçóes do paciente, promovendo a segurança do paciente, como observado a seguir:

É bem difícil, comunicação é algo que em tudo é difícil. Então você tem que ter algum instrumento que te oriente a fazer a passagem de plantão em uma ordem que não se perca algumas informaçóes. Então eu acho que um instrumento talvez com as principais informaçôes seria bom. (E2ENF)

[...] Então se a gente tivesse meio que definido o que é para ser passado e para todo mundo seguir mais ou menos, eu acho que seria melhor e talvez até sobraria tempo de falar algumas questóes que possam surgir. (E5FARM)

Eu acho que deveria ter uma padronização, porque senão as pessoas ficam falando coisas que são desnecessárias, que não acrescentam em nada a quem vai pegar o plantão. (E6FARM)

Eu acho que essa questão de padronização talvez fosse interessante, de realmente ter um roteiro do que falar, o que é importante. (E7PSICO) 
Talvez seja interessante a criação de algum método, até para facilitar para vocês [enfermeiros], um checklist, mas na verdade para a gente, a gente já consegue pegar bastante coisa na passagem de plantão, pelo menos como eu falei, dos pacientes que têm determinada demanda, considerando a passagem de plantão e o que a gente conversa com o paciente também. (E15NUTRI)

\section{Discussão}

A primeira categoria traz aspectos acerca da importância da participação da equipe multiprofissional no momento da passagem de plantão no serviço de emergência. A construção de um trabalho em equipe é um processo que exige tempo e que nem sempre é alcançado, pois está sujeito às interaçóes da equipe e às influências da instituição e dos processos sociais e históricos ${ }^{10}$. Para tanto, oferecer condiçóes propícias para o desenvolvimento do sentido de comunidade nas equipes é também promover o pertencimento, contribuir para a constituição de identidade profissional, elevar a autoestima, satisfazer necessidades e possibilitar a construção e promoção da saúde do trabalhador ${ }^{10}$.

A participação da equipe multiprofissional na passagem de plantão representa para muitos profissionais um momento para a elaboração de plano de cuidados aos pacientes para o dia ${ }^{11}$. Isso representa uma cultura organizacional positiva, um constante desafio, que requer avaliação permanente, em que pesem valores, hábitos, crenças, normas e experiências vivenciadas e compartilhadas pelos gestores e profissionais das organizações ${ }^{11}$.

A prática interprofissional colaborativa em saúde caracteriza-se como uma estratégia de grande importância na área da saúde por permitir reversão ao modelo de atenção em saúde hegemônico, possibilitando, assim, aumentar a resolutividade do trabalho em equipe, respeitando-se a integralidade do cuidado ${ }^{12}$. Com esse movimento, objetiva-se a superação de modelos dominantes de educação e prática uniprofissional, já que estes não atendem mais aos desafios e à complexidade das necessidades de saúde ${ }^{13}$.

Nesse sentido, torna-se fundamental que as equipes de saúde criem espaços e oportunidades para a arte de dialogar. Também é fundamental explorar as potenciais oportunidades para uma comunicação interprofissional, como promover reuniôes frequentes nas equipes, discutir casos, tomar decisôes compartilhadas e procurar a educação permanente com momentos de elucidação interprofissional, proporcionando assim um trabalho pautado na prática colaborativa em saúde ${ }^{12}$.

Os resultados do estudo reconheceram a equipe de enfermagem como captadora de demandas do paciente para a equipe multiprofissional. A equipe de enfermagem, tradicionalmente responsável pela passagem de plantão no ambiente hospitalar, é reconhecida pela equipe multiprofissional como a captadora das demandas dos pacientes, pois em seu trabalho é a profissão que permanece mais tempo no cuidado direto ao paciente. Por isso, a passagem de plantão da equipe de enfermagem ocorre com a finalidade de transmitir de forma objetiva e concisa dados assistenciais e gerenciais sobre intervençóes e condutas adotadas durante um turno de trabalho, cujo conhecimento permite a continuidade do cuidado pela equipe que inicia outro turno de trabalho ${ }^{3}$. 
Durante a passagem de plantão, a enfermagem abre espaço para outros profissionais colocarem-se, contribuírem com informações sobre as condições dos pacientes e até mesmo compartilharem seus cuidados. É importante destacar a relevância do desempenho dos profissionais, em especial, do enfermeiro, que é responsável pela orientação, supervisão, distribuição e coordenação das atividades da equipe de enfermagem; assistência direta e indireta aos usuários; interação com a equipe multiprofissional; e articulação intersetorial dos serviços hospitalares ${ }^{3}$.

A segunda categoria discute aspectos relacionados à importância da padronização das informações na passagem de plantão para a segurança do paciente na continuidade do cuidado.

Os participantes do estudo relatam que a dificuldade da equipe multiprofissional na passagem de plantão está imbricada com a não padronização das informaçóes do paciente. A padronização da passagem de plantão pode ter impacto positivo em muitos processos e resultados no cuidado, materializados, por exemplo, na melhora da comunicação, redução das complicações, eliminação de atrasos na admissão do paciente, melhora da compreensão das condiçôes de saúde, uso mais efetivo do tempo e menor duração da passagem de plantão ${ }^{14}$.

Os profissionais participantes deste estudo revelam a falta de conhecimento sobre o procedimento operacional padrão para a passagem de plantão no ambiente de atuação. Estudo realizado a partir da percepção de enfermeiros sobre procedimento operacional padrão no ambiente hospitalar evidenciou que os profissionais da saúde da equipe multiprofissional reconhecem a importância de uma equipe qualificada para a implementação dos protocolos, diminuindo os problemas existentes com relação ao cuidado com os pacientes, priorizando a qualidade do atendimento ${ }^{15}$.

Em relação à troca de informações sobre os pacientes entre as equipes multiprofissionais, foi possível analisar uma importante dimensão da cultura de segurança do paciente, que é a sua relação com o processo de comunicação. As linhas de comunicação e o trabalho em equipe internamente nas unidades de trabalho são elementos de aspecto favorável à cultura de segurança do paciente. Todavia, as linhas de comunicação e a colaboração entre equipes externas ao setor laboral, bem como alguns aspectos relacionados à passagem de plantão, postam-se como barreiras ao atendimento seguro sistêmico na organização ${ }^{16}$. Para tanto, há necessidade de incremento da comunicação entre equipes e unidades distintas na organização hospitalar, além do favorecimento de medidas que confluam à completude da passagem de plantão no bojo de cada setor ${ }^{16}$.

A segunda meta da Aliança Mundial para a Segurança do Paciente informa o quanto a comunicação é de extrema importância, pois ela ocorre a todo momento de forma direta ou indireta ${ }^{17}$. Por esse motivo, fica evidente que as falhas no processo de comunicação comprometem a segurança do paciente, tornando-se a maior causa de eventos adversos ${ }^{17}$.

Em 2013, o Ministério da Saúde criou o Programa Nacional de Segurança do Paciente (PNSP), por meio da Portaria no 529, com o objetivo de monitorar e prevenir os danos na assistência à saúde por meio da implantação da gestão de risco e de 
Núcleos de Segurança do Paciente (NSP) nos estabelecimentos de saúde ${ }^{18}$. Essas iniciativas permeiam a ampliação das ações de segurança do paciente e a disseminação de informações e conhecimentos para a comunidade em geral, além da inclusão do tema no ensino técnico e de graduação e pós-graduação na área da saúde ${ }^{18}$.

Também no ano de 2013 foi instituída a Resolução da Diretoria Colegiada no 36 , que tem por objetivo implementar ações para a promoção da segurança do paciente e a melhoria da qualidade nos serviços de saúde. Essa Resolução cria os NSP, que, entre as suas competências, consta o desenvolvimento de açóes para a integração e a articulação multiprofissional no serviço de saúde ${ }^{19}$. Além do mais, o NSP elabora o Plano de Segurança do Paciente (PSP) em Serviços de Saúde, e, dentre suas atividades, institui ações para melhorias na comunicação entre profissionais do serviço de saúde e entre serviços de saúde ${ }^{19}$.

Os profissionais deste estudo ressaltaram a necessidade da elaboração de uma metodologia de passagem de plantão que contemple a equipe multiprof issional. Sendo a passagem de plantão uma estratégia essencial no planejamento do cuidado seguro ao paciente, pode-se realizar um checklist elaborado que contemple informações essenciais para conhecer a situação clínica do paciente ${ }^{20}$.

Uma ferramenta de passagem de plantão muito utilizada mundialmente é o Situation, Background, Assessment and Recommendation (SBAR) ${ }^{21}$. Trata-se de um método estruturado para realizar a comunicação de informaçôes críticas que exigem atenção e ação imediatas, contribuindo para o gerenciamento das atividades da equipe de saúde e proporcionando maior segurança do paciente ${ }^{21}$. O SBAR permite uma estruturação da comunicação para que se possa reduzir as chances de erros e omissóes durante a passagem de plantão ${ }^{21}$.

$\mathrm{Na}$ instituição na qual foi realizada o presente estudo, os participantes citaram a existência de um documento de Procedimento Operacional Padrão para a realização da passagem de plantão na emergência. No entanto, nenhum dos participantes citou o método de SBAR, o que sugere desconhecimento dessa metodologia de passagem de plantão pela equipe multiprofissional.

Além do mais, a comunicação deve ser considerada como um dos instrumentos também do trabalho em saúde como um todo. É a partir dela que se estabelecem relações entre profissionais e usuários, assim como entre os profissionais da própria equipe multiprofissional e desta com a instituição. Por meio da comunicação, são desencadeadas ações compartilhadas e intervençôes que podem favorecer o cuidado adequado e resolutivo. Nesse sentido, torna-se fundamental o aprimoramento das habilidades de comunicação, para que todos esses processos interpessoais possam ser facilitados ${ }^{3}$.

A constituição de sujeitos comunicativos com capacidade reflexiva é caracterizada como um processo dialógico, pedagógico e político. A comunicação e argumentação como forma de liderança pertencem ao mundo do sistema de Habermas, resultante da razão normativa na qual predominam as leis e os códigos de ética profissionais ${ }^{22,23}$. 
Os manuais de Teoria Geral da Administração dão ênfase a elementos de gestão instrumental e burocrática; ao formato de empresas; ao papel individual dos gerentes e empreendedores; ao controle, à eficiência e ao desempenho como critérios básicos organizacionais $^{22}$. No entanto, os elementos entendimento, comunicação, diálogo e solidariedade contribuem para o rompimento dessa forma paradigmática vigente, em prol da ação comunicativa e da ação dialógica de caráter aberto, permitindo criticidade. Além disso, os atos comunicativos possuem um caráter de aprendizagem e conscientização ${ }^{22}$.

Nessa linha de pensamento, é importante pontuar a importância das instituiçóes de ensino como espaços privilegiados para o desenvolvimento enquanto sujeito e como grupo social, contribuindo para que o ser humano possa atuar com um nível maior de racionalidade comunicativa e ética ${ }^{23}$. Nos espaços de ensino e atuação acadêmica/profissional, a ação comunicativa, por meio da relação dialógica, resulta em uma nova intersubjetividade e ao mesmo tempo estimula uma reflexão crítica sobre a realidade concreta a ser transformada ${ }^{23}$.

A relação humanizadora, a capacidade de trabalhar em equipe multiprofissional, a participação em processos de gerência de políticas e serviços de saúde e preocupaçôes com a formação continuada são aspectos fundamentais para um exercício profissional socialmente qualificado ${ }^{23}$. Porém, apesar da importância da comunicação, o fato de ela ainda ser apontada como um entrave nos trabalhos multiprofissionais pode indicar que as discussões sobre comunicação e trabalho em equipe ainda se concentram nos cenários de formação acadêmica. Assim, é importante o investimento em educação permanente e realização de capacitaçóes nos cenários de cuidado hospitalares com foco e em prol da multidisciplinaridade para o cuidado em saúde.

\section{Considerações finais}

Os resultados do presente estudo apontam para a pouca contribuição dos integrantes da equipe multiprofissional durante o momento da passagem de plantão em um serviço hospitalar de emergência e para a possível relação dessa questão com a cultura organizacional. Sendo assim, esse paradigma deve ser trabalhado dentro da instituição com vistas a promover debates sobre o tema, visando à mudança de paradigmas instituídos culturalmente. Além do mais, ao mesmo tempo em que se espera uma maior participação dos integrantes da equipe multiprofissional durante a passagem de plantão, o tempo é considerado insuficiente para que esta comunicação aconteça de forma efetiva e em contexto multiprofissional.

Alguns aspectos foram abordados como facilitadores para uma passagem de plantão efetivamente multiprofissional, sendo esses a confiança interprofissional, a promoção de espaço que favoreça a contribuição da equipe multiprofissional com falas e momentos para tirar dúvidas e a assiduidade da equipe. 
A construção de Procedimentos Padrões Operacionais relacionados ao processo de comunicação entre equipes multiprofissionais durante a passagem de plantão deve também contemplar informaçôes sobre como os profissionais da nutrição, psicologia, farmácia e serviço social podem contribuir na passagem de plantão. Assim, será possível a promoção de um espaço para discussão multiprofissional, e não apenas uma discussão de enfermeiro para enfermeiro e entre a equipe de enfermagem.

Em relação a essa temática, os Procedimentos Padróes Operacionais possuem o objetivo de orientar a atuação dos profissionais para uma padronização dos procedimentos, porém, essas informações devem ser também disseminadas para a equipe, contemplando assim as práticas de educação permanente e continuada em serviços de saúde. Ressalta-se assim a importância de se mantê-los atualizados e disseminados aos integrantes das equipes, para que se possa fazer cumprir o que está proposto pela instituição e assim haver uma maior fiscalização de como ocorre o trabalho e o cumprimento dos deveres e alcance das metas propostas institucionalmente.

Os resultados do presente estudo nos levam a ponderar a diferença entre comunicação e informação. A transmissão de informaçốes pode ser padronizada; já a comunicação é baseada na interação e conexão entre os profissionais do setor, envolvendo também as habilidades de comunicação de cada indivíduo. Portanto, a passagem de plantão contempla essas duas dimensóes, sendo assim necessário o aperfeiçoamento das habilidades de comunicação atrelado à padronização e sistematização da passagem de plantão.

No decorrer da realização desta pesquisa, estudou-se uma prática uniprofissional a partir de uma perspectiva multiprofissional, ou seja, no cenário estudado a passagem de plantão é realizada pela enfermagem e as experiências multiprofissionais ainda são isoladas. Contudo, o presente estudo poderá contribuir para essa expansão, no sentido de levar aos profissionais a pensar em práticas efetivamente multiprofissionais, podendo a passagem de plantão já ocorrer nessa perspectiva e na possibilidade de contribuição dos demais profissionais participantes.

\section{Contribuições dos autores}

Todos os autores participaram ativamente de todas as etapas de elaboração do manuscrito.

\section{Direitos autorais}

Este artigo está licenciado sob a Licença Internacional Creative Commons 4.0, tipo BY (https://creativecommons.org/licenses/by/4.0/deed.pt_BR).

(cc) BY 


\section{Referências}

1. Machado MH, Ximenes Neto FRG. Gestão da educação e do trabalho em saúde no SUS: trinta anos de avanços e desafios. Cienc Saude Colet. 2018; 23(6):1971-80.

2. Lima AA, Santos de Jesus D, Silva TL. Densidade tecnológica e o cuidado humanizado em enfermagem: a realidade de dois serviços de saúde. Physis. 2018; 28(3):1-15.

3. Silva MR, Rodovalho APN, Alves LR, Camelo SHH, Laus AM, Chaves LDP. Passagem de plantão em enfermagem hospitalar: uma revisão integrativa. CuidArte Enferm. 2017; 11(1):122-30.

4. Barbosa PMK, Barbosa VBA, Sores FV, Sales PRS, Barbosa FK, Silva LCP. Organização do processo de trabalho para passagem de plantão utilizando escore para dependência e risco clínico. Rev Adm Saude. 2013; 15(58):19-26.

5. Beccaria LM, Meneguesso B, Barbosa TP, Pereira RAM. Interferências na passagem de plantão de enfermagem em unidade de terapia intensiva. CuidArte Enferm. 2017; 11(1):86-92.

6. Gonçalves MI, Rocha PK, Anders JC, Kusahara DM, Tomazoni A. Comunicação e segurança do paciente na passagem de plantão em unidades de cuidados intensivos neonatais. Texto Contexto Enferm. 2016; 25(1):1-8.

7. Tong A, Flemming K, McInnes E, Oliver S, Craig J. Enhancing transparency in reporting the synthesis of qualitative research: ENTREQ. BMC Med Res Methodol. 2012; 12:181-8.

8. Minayo MCS, organizadora. Pesquisa social: teoria, método e criatividade. 34a ed. Petrópolis: Vozes; 2015.

9. Brasil. Ministério da Saúde. Resolução no 466, de 12 de Dezembro de 2012. Brasília: Ministério da Saúde; 2012.

10. Wanderbroocke ACNS, Baasch C, Antunes MC, Menezes M. O sentido de comunidade em uma equipe multiprofissional hospitalar: hierarquia, individualismo, conflito. Trab Educ Saude. 2018; 16(3):1157-76.

11. Nogueira JWS, Rodrigues MCS. Comunicação efetiva no trabalho em equipe em saúde: desafio para a segurança do paciente. Cogitare Enferm. 2015; 20(3):636-40.

12. Previato GF, Baldissera VDA. A comunicação na perspectiva dialógica da prática interprofissional colaborativa em saúde na atenção primária à saúde. Interface (Botucatu). 2018; 22 Supl 2:1535-47.

13. Câmara AMCS, Cyrino AP, Cyrino EG, Azevedo GD, Costa MV, Bellini MIB, et al. Educação interprofissional no Brasil: construindo redes formativas de educação e trabalho em saúde. Interface (Botucatu). 2016; 20(56):9-12.

14. Halm MA. Nursing handoffs: ensuring safe passage for patients. Am J Crit Care. 2013; 22(2):158-62.

15. Walter RR, Gehlen MH, Ilha S, Zamberlan C, Freitas HMB, Pereira FW. Procedimento operacional padrão no ambiente hospitalar: percepção de enfermeiros. Rev Online Pesqui Cuid Fundam. 2016; 8(4):5095-100.

16. Bohrer CD, Marques LGS, Vasconcelos RO, Oliveira JLC, Nicola AL, Kawamoto AM. Comunicação e cultura de segurança do paciente no ambiente hospitalar: visão da equipe multiprofissional. Rev Enferm UFSM. 2016; 6(1):50-60.

17. World Health Organization. World Alliance for Patient Safety: forward programme. Genebra: WHO; 2005.

18. Brasil. Ministério da Saúde. Portaria no 529, de 1 de Abril de 2013. Institui o Programa Nacional de Segurança do Paciente (PNSP). Brasília: Ministério da Saúde; 2013.

19. Brasil. Ministério da Saúde. Resolução RDC no 36, de 25 de Julho de 2013. Institui açốes para a segurança do paciente em serviços de saúde e dá outras providências. Brasília: Ministério da Saúde; 2013.

20. Silva SG, Nascimento ERP, Hermida PMV, Sena AC, Klein TCR, Pinho FM. Checklist para passagem de plantão de pacientes em pós-operatório imediato na admissão em terapia intensiva. Enferm Foco. 2016; 7(1):13-7.

21. Raymond M, Harrison MC. The structured communication tool SBAR (Situation, Background, Assessment and Recommendation) improves communication in neonatology. S Afr Med J. 2014; 104(12):850-2.

22. Andrade LFS, Alcântara VC, Pereira JR. Comunicação que constitui e transforma os sujeitos: agir comunicativo em Jürgen Habermas, ação dialógica em Paulo Freire e os estudos organizacionais. Cad EBAPE. 2019; 17(1):12-24.

23. Menezes Junior AS, Brzezinski I. A teoria do agir comunicativo e a formação médica: análise crítica das competências curriculares e da relação médico-paciente. EccoS Rev Cient. 2018; 1(47):441-56. 
The aim of the study was to learn more about the multiprofessional team's perspective on shift turn in the emergency service of a university hospital. This was an exploratory and descriptive study with qualitative approach. A total of 15 members of the multiprofessional team were interviewed. Using the content analysis technique, two categories were identified: importance of the multiprofessional team's active participation in the shift turn, and lack of information standardization in the shift turn for the patient's safety in the continuity of care. The results indicate low contribution of the multiprofessional team in the shift turn, being possibly related to the organizational culture. Interprofessional trust, promotion of a space that favors the multiprofessional team contribution to discourses and moments to answer questions, and the team's assiduity are considered facilitators of an effectively multiprofessional shift turn.

Keywords: Communication. Patient safety. Patient care continuity. Patient care team. Emergency nursing.

El objetivo del estudio fue conocer la perspectiva del equipo multiprofesional sobre el cambio de turno en el servicio de urgencias de un hospital universitario. Estudio exploratorio y descriptivo, con abordaje cualitativo. Fueron entrevistados 15 integrantes del equipo multiprofesional. Por medio de la técnica de análisis de contenido se identificaron dos categorías: Importancia de la participación activa del equipo multiprofesional para el momento del paso de turno; Ausencia de estandarización de las informaciones en el paso de turno para la seguridad del paciente en la continuidad del cuidado. Los resultados señalan poca contribución del equipo multiprofesional en el cambio de turno, pudiendo estar relacionado con la cultura organizacional. La confianza interprofesional, la promoción de espacio que favorezca la contribución del equipo multiprofesional con diálogos y momentos para solucionar duras y la asiduidad del equipo son aspectos abordados como facilitadores para un cambio de turno efectivamente multiprofesional.

Palabras-clave: Comunicación. Seguridad del paciente. Continuidad de la asistencia al paciente. Equipo de asistencia al paciente. Enfermería en urgencias. 